\title{
STANDALONE PHOTOVOLTAIC BASED AIR COOLER WITH WATER PUMPING SYSTEM
}

\author{
M Gowtham \\ Assistant Professor \\ Department of Electrical and Electronics Engineering \\ Selvam College of Technology, Namakkal, \\ Tamilnadu, India.
}

\begin{abstract}
Modified MISO DC-DC converter based Photo Voltaic (PV) water pumping system is designed for population living in remote areas to fulfill their water pumping requirement for various applications like drinking water, water for irrigation and daily needs etc. With the objective of improvement in performance and efficiency of PV based water pumping system and thus to justify its installation cost, a modified Multi-input singleoutput (MISO) converter is proposed. Contribution of this paper is the implementation of proposed MISO converter to the conventional PV based water pumping system to enhance extraction of power from PV units under partial shading/mismatching phenomena without any energy storage device. Various irradiation patterns are considered to create the mismatching conditions and observe the performance of designed system. To verify the performance of proposed MISO converter, designed system is simulated in MATLAB/SIMULINK environment. Simulation results show that the implementation of proposed MISO converter instead of conventional DC-DC converter based PV water pumping system increases the extracted power from PV units under mismatching phenomena.
\end{abstract}

Keywords -- Multi-input single-output (MISO) converter, Photovoltaic (PV), water pumping, BLDC motor-pump.

\section{INTRODUCTION}

The last few decades have seen immense developments and advancements in technology. Having said that, currently over 900 million people in different countries do not have access to clean water for drinking, irrigation and other purposes. Out of these a large population still lives in rural areas where the only source of water is either from the rains or from the rivers. To make matters worse a large number of rural areas of countries like India, are yet to be connected to the respective National Power grids. On top of that the Fossil era is coming to an end. Key factors that impact the industry of power generation are limited availability of fossil fuels, environmental impact by the conventional power generating systems and an increase in power demands over time. There is a silver lining though the recent technological advancements in power electronics have led to the development and usage of renewable energy
S Dhanushree

PG Student

Department of Electrical and Electronics Engineering

P.G.P College of Engineering and Technology,

Namakkal, Taminadu, India.

sources. These days country's development is measured in terms of electricity it produces and or makes available to its citizens. It is a grim reality that most of the farmers, who actually constitute a bigger part of India's total population, are solely dependent on the rains for irrigation, due to the unavailability of electricity in rural India. Thus it provides an opportunity for the Standalone Photovoltaic (PV) based water pumping system to be an effective solution to this problem for the areas that have a considerable amount of irradiation but no access to the national grid. Battery storage combined with DC motors and some control equipment is the core of most of the commercially available solar based water pumping systems these days. One possible configuration could be a PV pumping system with a single-switch non- isolated DC-DC converter powered by a standalone battery as proposed in [3]. The battery storage allows maximization of output PV power however it proves to be costly in terms of the life span of the battery which is around 2 years and needs a timely replacement. Another approach is the Synchronous motor based PV water pumping systems which delivers higher efficiency as discussed in [4]. Though the maintenance cost factored in terms of battery storage is low however the initial cost of the system altogether is too much for a rural investment. The good part with this system is that its reliability and efficiency could be improved using variable speed drives instead of the Synchronous motor which are available in market. Various types of pumps sets and motors are available in the market these days. PMBLDC or permanent magnet brushless DC motor is the most commonly used motor type. A single stage PV water pumping system based on an induction motor uses an inverter for both Maximum Power Point Tracking (MPPT) and DC to AC conversion.

MPPT algorithm has also been incorporated in PV water pumping system in order to increase the extraction of power from PV panels. On the basis of energy utilization, performance characteristics and the stability for standalone PV pumping system, an exhaustive comparison between direct duty ratio perturbation and reference voltage perturbation is carried out. A parallel connected photovoltaic system (PCPVS) configuration based PV water pumping system with conventional DC-DC converter is shown in Fig. 1. Two series 


\section{International Journal of Engineering Applied Sciences and Technology, 2019 \\ Vol. 4, Issue 7, ISSN No. 2455-2143, Pages 130-135 \\ Published Online November 2019 in IJEAST (http://www.ijeast.com)}

Connected PV modules results in one PV unit and such two PV units are connected in series to form one PV array. Further two PV arrays are connected in parallel to form PCPVS.

Extraction of power from PV units is effective only at uniform irradiation which is not the case in practical scenario. Due to the problems of partial shading or mismatching in parallel and series connected PV modules; the performance of such system (Fig. 1) reduces appreciably.

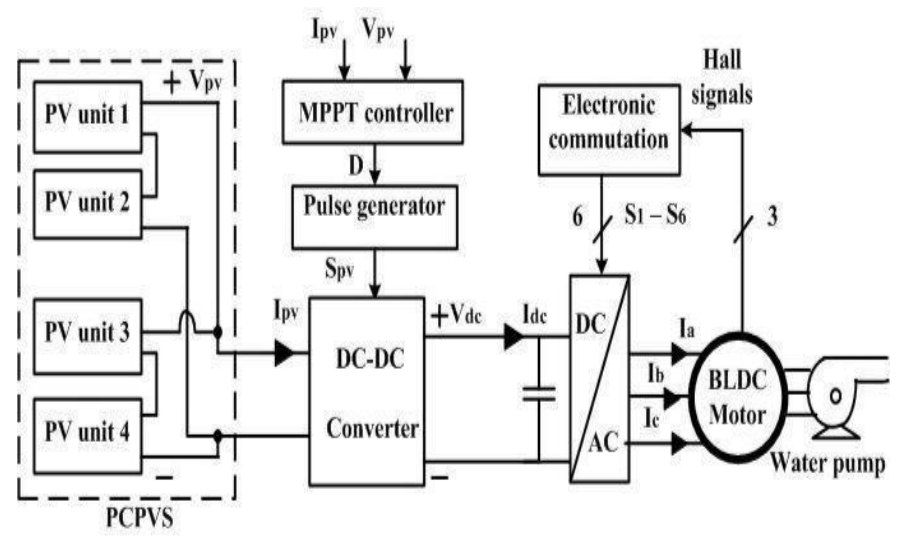

Fig. 1. Schematic of conventionl DC-DC converter based PV water pumping system

To address the limitation of reduction in extracted PV power from PCPVS under mismatching conditions, this work proposed a Multi-input single-output (MISO) DC-DC converter.

The main contribution of this paper is as follows:

- A combination of series and parallel connected PV modules is considered, to optimize the PV configuration and represent a practical scenario.

- With implementation of proposed MISO converter, better extraction of power from PV units is achieved under mismatching conditions.

- Improved power extraction indicates the reduction in power losses occurred due to mismatching or partial shading in parallel connected PV modules.

- Proposed system configuration does not need any bypass and blocking diode.

The outline of the paper is as follows. Section II presented the structure of the designed PV water pumping system, ratings of the system components and its operation. Configuration, component ratings and other details of the proposed MISO converter are given in section III. To verify the performance of the designed system, simulation results are presented in section IV. Comparison of proposed MISO converter based PV water pumping system with conventional DC -DC converter based PV water pumping system is carried out on the basis of extracted PV power from each PV unit under mismatching condition. Section $\mathrm{V}$ concludes the achievements and limitations/ future scope of the proposed system.

\section{SYSTEM DESCRIPTION AND OPERATION}

Schematic of the proposed MISO converter based PV water pumping system is presented in Fig. 2. The designed system consist of four PV units (representing PCPVS of Fig. 1), proposed MISO DC-DC converter, a 3-phase inverter, BLDC based motor -pump system and two controllers i.e. MISO controller and inverter controller. Each PV unit consists of two series connected PV modules. Implementation of proposed MISO converter contributes in reduction of power losses caused due to mismatching in case of parallel connected PV arrays.

In order to ensure maximum power extraction from PCPVS, Perturb and observe ( $\mathrm{P} \& \mathrm{O})$ algorithm based MPPT is implemented through MISO controller and inverter controller controls the operation of BLDC motor-pump system. Voltage and current sensors are required to sense PV unit voltage and current values respectively. The $\mathrm{P} \& \mathrm{O}$ algorithm requires feedback of PV current and voltage for calculation of duty ratio to implement MPPT. To feed the BLDC motor, a DC-AC converter converters the DC output of MISO converter into $\mathrm{AC}$. The DC-AC converter is operated through an electronic commutation of BLDC motor assisted by its built -in encoder and thus eliminating the losses due to high frequency switching. The control philosophy of DC-AC converter and operation of BLDC motor is beyond the scope of this paper and more details on the same can be found in [6].

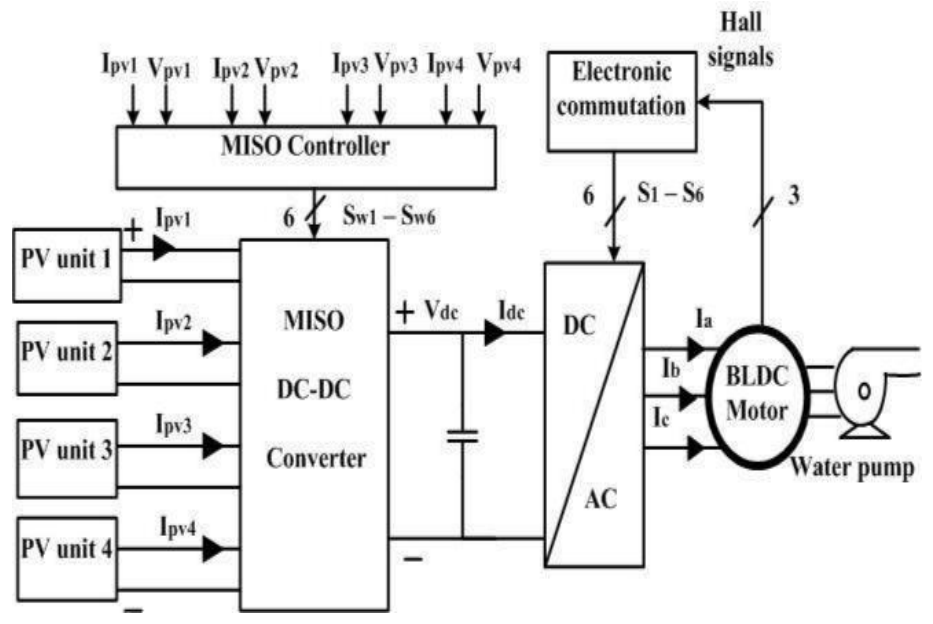

Fig. 2. Schematic of proposed MISO DC-DC converter based PV water pumping

In the designed system (Fig. 2), two PV modules are connected in series to represent one PV unit. The seriesparallel configuration i.e. PCPVS depicted in Fig. 1 is achieved here in designed system at MISO converter stage. In 


\section{International Journal of Engineering Applied Sciences and Technology, 2019 \\ Vol. 4, Issue 7, ISSN No. 2455-2143, Pages 130-135 \\ Published Online November 2019 in IJEAST (http://www.ijeast.com)}

other words direct series-parallel connection of PCPVS is avoided at input stage and similar is achieved through MISO converter configuration. Specification of each PV module is given in Table I. One PV array is contributing to $1.2 \mathrm{~kW}$ and thus the complete power rating of the considered PCPVS is $2.4 \mathrm{~kW}$ at Standard test condition (STC) i.e. at irradiation of $1000 \mathrm{~W} / \mathrm{m}^{2}$ and ambient temperature as $25^{\circ} \mathrm{C}$. In the system all PV modules are considered same and identical to consider the Ideal possible situation. When PV modules are connected in series, impact of partial shading/mismatching is more as compared to when PV modules are connected in parallel configuration.

Table -1 Specification of each module

\begin{tabular}{|l|l|}
\hline Maximum power, $\mathrm{P}_{\text {mppt }}(\mathrm{W})$ & 305 \\
\hline Voltage at MPP, $\mathrm{V}_{\text {mppt }}(\mathrm{V})$ & 54.7 \\
\hline Open circuit voltage $\mathrm{V}_{\mathrm{oc}}(\mathrm{V})$ & 64.2 \\
\hline Current at MPP, $\mathrm{I}_{\mathrm{mppt}}(\mathrm{A})$ & 5.58 \\
\hline Short circuit current, $\mathrm{I}_{\mathrm{sc}}(\mathrm{A})$ & 5.96 \\
\hline $\begin{array}{l}\text { Number of PV cells connected in } \\
\text { series, } \mathrm{N}_{\mathrm{s}}\end{array}$ & 96 \\
\hline Series resistance, $\mathrm{R}_{\mathrm{S}}(\Omega)$ & 0.037998 \\
\hline Parallel resistance, $\mathrm{R}_{\mathrm{P}}(\Omega)$ & 993.51 \\
\hline Saturation current, $\mathrm{I}_{\mathrm{sat}}(\mu \mathrm{A})$ & 0.011753 \\
\hline PV unit power $(\mathrm{W})$ & 610 \\
\hline PV unit $\mathrm{V}_{\mathrm{mppt}}(\mathrm{V})$ & $54.7 * 2$ \\
\hline PV unit $\mathrm{I}_{\text {mppt }}(\mathrm{A})$ & 5.58 \\
\hline
\end{tabular}

Despite of consideration that all PV modules are used are identical in nature, mismatching phenomena reflects a difference/change in effective current flow through the PV arrays constructed from series connection of PV modules. When such PV arrays are connected in parallel, resultant will be less extraction of power under varying irradiation condition as compared to uniform irradiation, due to the phenomena of partial shading in PCPVS.

\section{PROPOSED MISO DC-DC CONVERTER}

Due to the intermittent nature of PV power, it is not possible to obtain a constant $\mathrm{DC}$ voltage $\left(\mathrm{V}_{\mathrm{dc}}\right)$ at common $\mathrm{DC}$ bus. In order to regulate the $\mathrm{V}_{\mathrm{dc}}$ to ensure maximum power extraction from PV modules, a DC-DC converter as an intermediate stage is generally used. PCPVS is feeding power to the inverter through proposed MISO converter. Application of MISO converter is beneficial to limit the impact of partial shading occurred due to the variation in effective insolation fallen on the PCPVS. Phenomena of partial shading may take place due to various factors like variation in PV module specifications, partial shading, difference in inclination angle, manufacturing issue etc.

Configuration of the proposed MISO converter is given in Fig. 3. $V_{p v 1}, V_{p v 2}, V_{p v 3}, V_{p v 4}$ and $I_{p v 1}, I_{p v 2}, I_{p v 3}, I_{p v 4}$ are the voltage across each PV unit and current through the each PV unit respectively. Four PV units are connected to the MISO converter and single output of MISO converter is connected to the common DC bus, thus resulting in MISO DC-DC converter. Four PV units connected to the proposed MISO converter are basically representing the equivalent of PCPVS shown in Fig. 1. In Fig. 2, it seems that all PV units are may be connected in series, but configuration of the proposed MISO converter ensure that these four PV units are equivalent to the PCPVS defined in Fig. 1.

Output terminals of MISO converter is connected to the inverter to fed power to the BLDC motor-pump system. P\&O based MPPT algorithm is implemented at MISO converter to ensure extraction of maximum power. Duty ratios $\mathrm{D}_{1}, \mathrm{D}_{2}, \mathrm{D}_{3}$, $\mathrm{D}_{4}$ are the outcome of $\mathrm{P} \& \mathrm{O}$ and with the help of Pulse width modulation (PWM), switching signals for $S_{p v 1}, S_{p v 2}, S_{p v 3}, S_{p v 4}$ $\mathrm{S}_{\mathrm{pv} 5}$ and $\mathrm{S}_{\mathrm{pv} 6}$ are further obtained.

Table -2 Parameter values of proposed MISO Converter

\begin{tabular}{|l|c|}
\hline $\begin{array}{l}\text { Inductor, } \\
\mathrm{L}_{1}=\mathrm{L}_{2}=\mathrm{L}_{3}=\mathrm{L}_{4}(\mathrm{mH})\end{array}$ & 0.9 \\
\hline Inductor, $\mathrm{L}_{5}(\mu \mathrm{H})$ & 312 \\
\hline Inductor, $\mathrm{L}_{6}(\mu \mathrm{H})$ & 700 \\
\hline $\begin{array}{l}\text { Capacitor, } \\
\mathrm{C}_{1}=\mathrm{C}_{2}=\mathrm{C}_{3}=\mathrm{C}_{4}(\mu \mathrm{F})\end{array}$ & 800 \\
\hline Capacitor, $\mathrm{C}(\mu \mathrm{F})$ & 5000 \\
\hline $\begin{array}{l}\text { Ipvl= Ipv2=Ipv3= Ipv4 } \\
(\mathrm{A}) \text { It STC and uniform shading })\end{array}$ & 5.58 \\
\hline Switching frequency, $\mathrm{f}_{\mathrm{S}}(\mathrm{kHz})$ & 4.6 \\
\hline
\end{tabular}

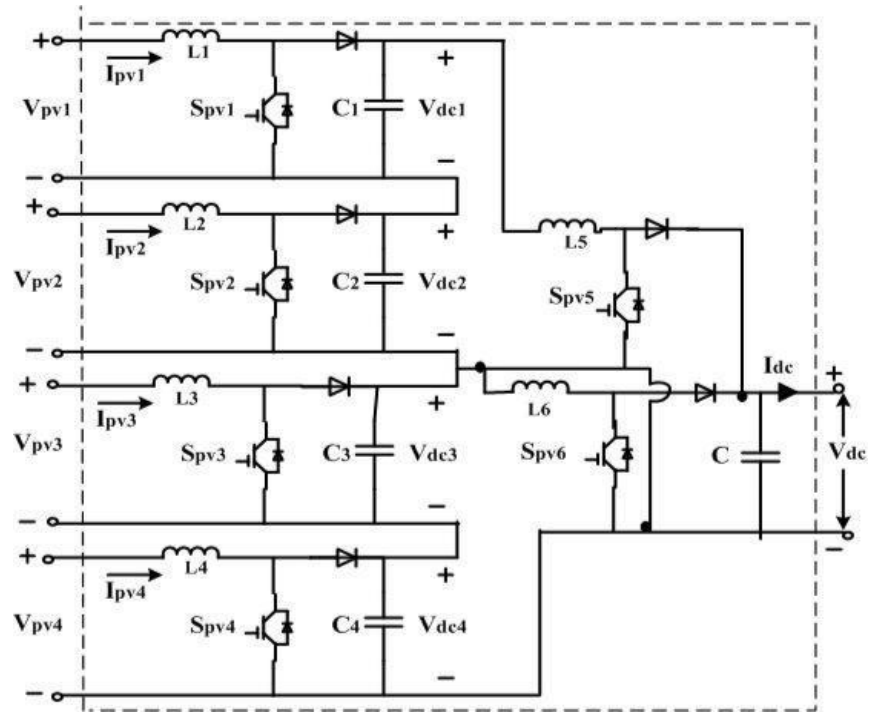

Fig. 3. Configuration of proposed MISO DC-DC converter IV. SIMULATION RESULTS AND DISCUSSION

To verify the performance of the proposed MISO converter based PV water pumping system as depicted in Fig. 2; conventional DC-DC converter based PV water pumping (Fig. 


\section{International Journal of Engineering Applied Sciences and Technology, 2019 \\ Vol. 4, Issue 7, ISSN No. 2455-2143, Pages 130-135 \\ Published Online November 2019 in IJEAST (http://www.ijeast.com)}

1) and proposed MISO converter based PV water pumping configuration (Fig.2) are simulated using MATLAB/SIMULINK environment.

Comparison between the performances of both the system configurations is carried out in terms of the PV power being extracted from individual PV units under mismatching condition. As mentioned in section III, all PV modules and thus PV units are considered identical, to depict the best possible condition. Mismatching condition among the four PV units is created by considering variation in irradiation.

Table -3 Considered irradiation to represent the mismatching condition

\begin{tabular}{|l|c|}
\hline $\begin{array}{l}\text { PV unit } \\
\text { number }\end{array}$ & $\begin{array}{l}\text { Incident } \\
\text { irradiation }\left(\mathbf{W} / \mathbf{m}^{\mathbf{2}}\right)\end{array}$ \\
\hline PV unit 1 & 800 \\
\hline PV unit 2 & 700 \\
\hline PV unit 3 & 700 \\
\hline PV unit 4 & 600 \\
\hline
\end{tabular}

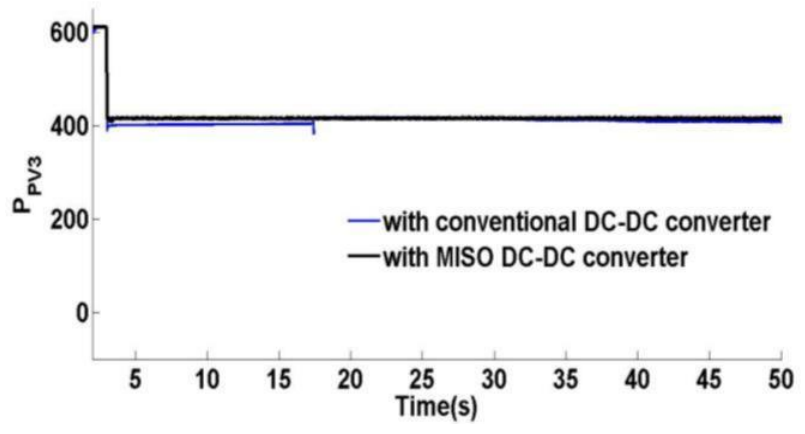

Fig. 4. Variation in PV unit 1 power with change in irradiation

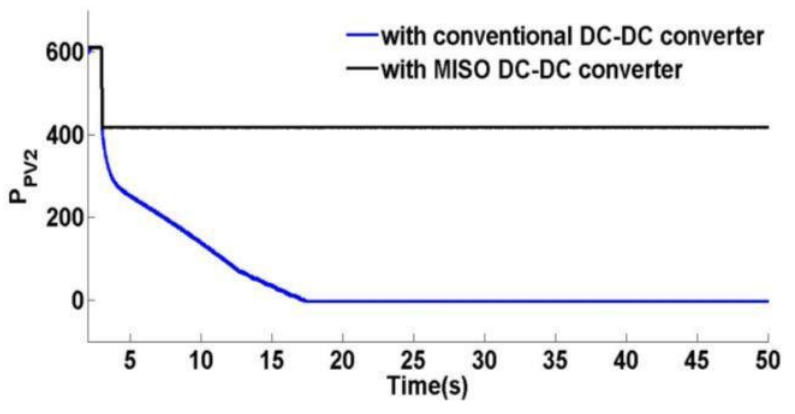

Fig. 5. Variation in PV unit 2 power with change in irradiation

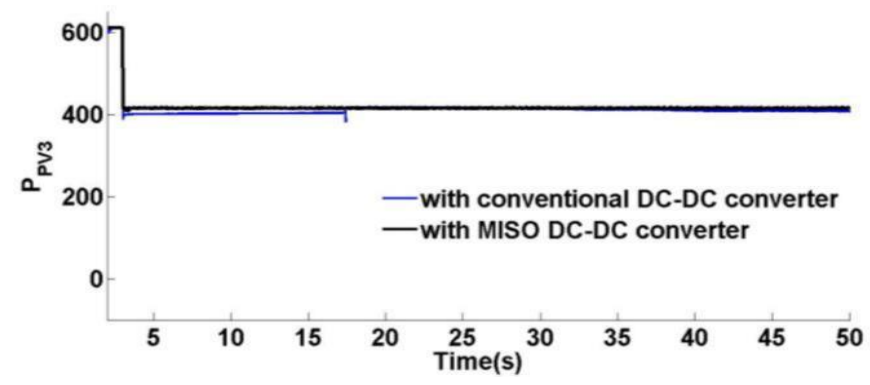

Fig. 6. Variation in PV unit 3 power with change in irradiation

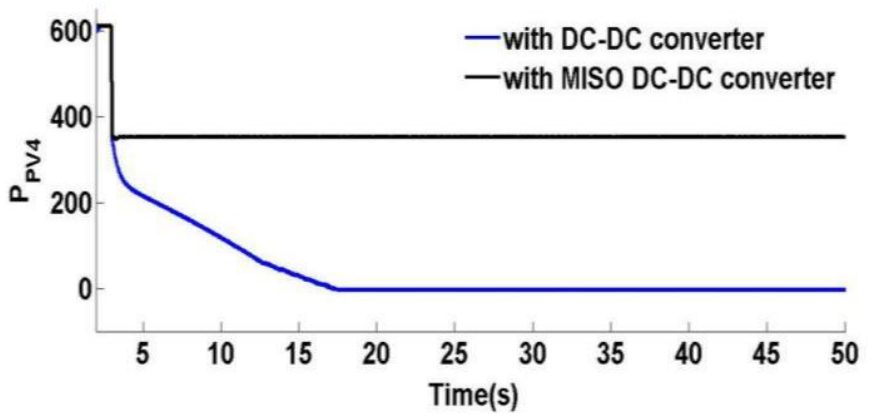

Fig. 7. Variation in PV unit 4 power with change in irradiation

Initially all $\mathrm{PV}$ units are operating at uniform irradiation of $1000 \mathrm{~W} / \mathrm{m}^{2}$ at STC. At $\mathrm{t}=3 \mathrm{~s}$, the irradiation is suddenly changed as per values considered in Table III. Steady state and dynamic performance of both the systems by simulating these cases are shown in Fig. $4 \& 5$.

It is important to note here that in the considered irradiation pattern, variation in irradiation is considered at both stages i.e. at series connected PV modules (PV unit level) and at parallel connected PV arrays (PCPVS) and thus considering the worst possible case of partial shading. Further in PCPVS of Fig.1, blocking diode in series with each PV array and bypass diode in anti-parallel across each PV unit, is also considered. Use of blocking diode helps in avoiding the revere flow of current and bypass diode helps in eliminating the effect of power consumption by partially shaded PV module.

Before $\mathrm{t}=3 \mathrm{~s}$ when uniform irradiation of $1000 \mathrm{~W} / \mathrm{m}^{2}$ falls, all PV units operate at MPPT and thus generates equal amount of power for both the considered cases. MISO controller and conventional DC- DC converter controller ensures MPPT operation for MISO based PV water pumping system and conventional DC-DC converter based water pumping system respectively. Hence an extraction of maximum possible power of $610 \mathrm{~W}$ from all four individual PV units is achieved for both cases. 


\section{International Journal of Engineering Applied Sciences and Technology, 2019 Vol. 4, Issue 7, ISSN No. 2455-2143, Pages 130-135 \\ Published Online November 2019 in IJEAST (http://www.ijeast.com)}

At $t=3 \mathrm{~s}$, insolation is changed for all four PV units as considered in Table III; a drop in power is expected. PV unit 1 and PV unit 3 (Fig. 4 and Fig. 6) continues to operate at MPPT. Power of $0.488 \mathrm{~kW}$ and $0.427 \mathrm{~kW}$ is extracted from PV unit 1 and PV unit 3 respectively. PV unit 1 and PV unit 3 both operate at new maximum power point for both the considered PV water pumping systems. Graph of PV power being extracted from PV unit 2 and PV unit 4 is shown in Fig. 5 and Fig. 7 respectively. Prior to $t=3 \mathrm{~s}$, PV unit 2 and PV unit 4, operates at MPPT and thus leads to extraction of 610 $\mathrm{kW}$ PV power from each PV unit and for both the system.

Further at $\mathrm{t}=3 \mathrm{~s}$, irradiation falls to $700 \mathrm{~W} / \mathrm{m}^{2}$ and $600 \mathrm{~W} / \mathrm{m}^{2}$ for PV unit 2 and PV unit 4 respectively. For MISO DC-DC converter based PV water pumping system, PV unit 2 and PV unit 4 still operates at MPPT. This was possible due to the implementation of proposed MISO converter and forming PCPVS through MISO converter stage (Fig. 2 and Fig. 3) instead at the input stage (Fig. 1). Thus proposed MISO DCDC eliminates the impact of partial shading in PCPVS.

However in the case of conventional DC-DC converter based $\mathrm{PV}$ water pumping system, PV power for PV unit 2 and PV unit 4 dropped to zero. In other words PV units 2 and 4 are neither consuming PV power nor producing PV power. This is due to the fact that PV unit 1 and PV unit 2 are connected in series and when the difference of current produced by these individual PV units are sufficiently large; the bypass diode corresponding to the PV unit with less irradiation (in our case PV unit 2) becomes forward biased. Thus total voltage drop across PV unit 2 is equivalent to forward biased voltage drop of diode connected across the PV unit. This leads to zero PV power extraction from PV unit 2 (Fig 5).

In this scenario PV unit 1 has full operating freedom and this further leads to operation of PV unit 1 at MPPT for conventional DC- DC converter based PV water pumping system. PV unit 3 and PV unit 4 operates in similar fashion as discussed for PV unit 1 and PV unit 2 respectively. Also in the absence of bypass diode, the voltage reversal across respective PV unit may take place depending upon the irradiation level and thus corresponding current level. In this case PV unit will consume power instead of being producing. Fig. 5 and Fig. 7, shows a large difference in power being extracted for both the cases being considered. In conventional DC-DC converter based PV water pumping system, series connection of two PV modules forms one PV unit and such two PV units are connected in series to form one PV array. Further two such PV arrays are connected in parallel to form PCPVS. Resultant terminals are then connected to the single input of conventional DC- DC converter. Mismatching in simulated case is considered at PV unit level. To avoid additional power loss, bypass and blocking diodes are also used. Refer Fig. 4-7, initially all PV units operate at MPPT, but at $\mathrm{t}=3 \mathrm{~s}$ partial shading occurs and MPPT controller of conventional DC-DC converter tries to operate all PV units at MPPT. As result PV unit 1 and PV unit 3 operates at MPPT but PV unit 2 and PV units 4 fails to operate at MPPT. Bypass diode across each PV unit avoids the reversal of voltage across each PV unit and thus consumption of power by PV unit 2 and PV unit 4 . As result PV unit 2 and PV unit 4 contributes zero in PV power being extracted.

However in the case with proposed MISO DC-DC converter based configuration (Fig. 2), due to implementation of proposed MISO converter direct parallel connection of both the PV arrays are avoided. As PV units are inter-connected through the MISO converter in the designed system, problem associated with partial shading/mismatching has been eliminated. This result in no additional power loss as in the case of conventional DC-DC converter based PV water pumping system. Implementation of MISO inverter in PV water pumping application will slightly increase the cost of the system, but as its addition will increase the extracted PV power. So, increase in cost will be easily compensated.

The total power generated from all the four PV units is 1.708 $\mathrm{kW}$ (after $\mathrm{t}=3 \mathrm{~s}$ ) for the proposed system while it is only $0.915 \mathrm{~kW}$ for conventional DC-DC converter based PV water pumping system. Thus an improvement of nearly $0.793 \mathrm{~kW}$ is seen with the simulation of proposed system configuration for the considered irradiation patterns. Such variation in irradiation/mismatching is a frequently occurring phenomena and may be caused due to various factors like partial shading, clouding effect, difference in PV module specification, inclination angle etc. A difference of $0.793 \mathrm{~kW}$ is sufficiently large enough to justify the application of proposed MISO DCDC converter. For further larger difference in insolation, the results are more and more promising with the proposed method. This is also remarkable that the said improvement in the extracted power also comes with an advantage of avoiding the application of blocking diode and bypass diodes. The proposed method involving MISO converter does not require blocking diodes in series with each PV array.

\section{CONCLUSION}

To improve the performance of PV based water pumping system, in this paper a modified MISO converter is proposed. Mismatching/partial shading in parallel connected PV array results in additional power losses and this power loss is even worst in case of configuration with series -parallel connections. This additional power loss under partial shading/mismatching reduces the amount of PV power being finally extracted from PV units. In the designed system, equivalent to series-parallel configuration of PV units is considered; but the implementation of proposed MISO converter avoids the direct parallel connection of PV arrays. Parallel connection of PV arrays is obtained at MISO converter stage. With the designed system all four PV units operate at MPPT and thus nullifying the impact of partial shading. It is validated from the simulation results that MISO converter helps in avoiding the loss of $0.793 \mathrm{~kW}$ as compared 


\section{International Journal of Engineering Applied Sciences and Technology, 2019 Vol. 4, Issue 7, ISSN No. 2455-2143, Pages 130-135 \\ Published Online November 2019 in IJEAST (http://www.ijeast.com)}

to conventional DC-DC converter based configuration considered, under mismatching/variation in isolation. Implementation of MISO converter will increase the cost as compared to conventional DC-DC converter, but this will be easily compensated by increase in PV power being extracted due to its application in the system. Also the proposed converter does not need use of any bypass and/or blocking diode.

\section{REFERENCES}

[1] M. Chunting, M. B. R. Correa, and J. O. P. Pinto, 2010, "The IEEE 2011 international future energy challengeRequest for proposals," in Proc.IFEC, (pp. 1-24).

[2] M. A. Vitorino and M. B. R. Correa, 2009 "High performance photovoltaic pumping system using induction motor," in Proc. Brazilian Power Electron.Conf., (pp. 797-804).

[3] Le An and Dylan Dah-Chuan Lu, February 2015, "Design of a Single-Switch DC/DC Converter for a PVBattery-Powered Pump System With PFM+PWM Control", IEEE Transactions on Industrial Electronics, Vol. 62, No. 2, (pp. 910-921).

[4] G. Teröde, K. Hameyer, and R. Belmans, 1999 "Sensorless control of a permanent magnet synchronous motor for PV-powered water pump systems using the extended Kalman filter," in Proc. 9th Int. Conf. Elect. Mach. Drives, (pp. 366-370).

[5] Alonso-Abella M, Chenlo F, Blanco J and Manso D, 1998, "Use of standard frequency converters in PV pumping systems," Proceedings of the $2^{\text {nd }}$ World Conference on Photovoltaic Solar Energy Conversion, Vienna, (pp. 3254-3257).

[6] A. Hadj Arab, M. Benghanem, and F. Chenlo, 2006, "Motor-pump system modelization," Renewable Energy, vol. 31, (pp. 905-913).

[7] A. B. Raju, S. Ramesh Karnik and Rohini Jyoti, 2008, "Maximum Efficiency Operation of A Single Stage Inverter Fed Induction Motor PV Water Pumping System", First International Conference on Emerging Trends in Engineering and Technology, (pp. 905-910).

[8] Sachin Jain, Ramsha Karampuri, and V. T. Somasekhar, February 2016, "An Integrated Control Algorithm for a Single-Stage PV Pumping System Using an Open-End Winding Induction Motor", IEEE Transactions on Industrial Electronics, Vol. 63, No. 2, (pp. 965-965).

[9] João Victor Mapurunga Caracas, Guilherme de Carvalho Farias, Luis Felipe Moreira Teixeira and Luiz Antonio de Souza Ribeiro, January/February 2014, "Implementation of a High-Efficiency, High-Lifetime, and Low-Cost Converter for an Autonomous Photovoltaic Water
Pumping System", IEEE Transactions on Industry Applications, Vol. 50, No. 1, (pp. 631-641).

[10] Mohammed A. Elgendy, Bashar Zahawi and David J. Atkinson, January 2012, "Assessment of Perturb and Observe MPPT Algorithm Implementation Techniques for PV Pumping Applications", IEEE Transactions on Sustainable Energy, Vol. 3, No. 1, (pp. 21-33).

[11] Esram T, Chapman PL., 2007, "Comparison of photovoltaic array maximum power point tracking techniques", IEEE Trans. Energy Conv., Vol. 22(2), (pp. 439-449).

[12] Y. Li, X. Ruan, D. Yang, F. Liu, and C.K. Tse, September 2010, "Synthesis of multiple input DC/DC converters," IEEE Transactions on Power Electronics, vol. 25, no. 9, (pp. 2372-2385).

[13]C. Liu and Y.M. Chen, January 2009, "A systematic approach to synthesizing multi input DC-DC converters," IEEE Transactions on Power Electronics, vol. 24, no. 1, (pp. 116-127). 